\title{
Experimental Research on Joint Mechanical Behavior of Container Structures
}

\author{
Ye LU ${ }^{1}$, GuoQiang $\mathrm{LI}^{1,2}$, Lei MAO ${ }^{1,3}$ \\ ${ }^{1}$ College of Civil Engineering, Tongji University, 1239 Siping Road, Shanghai, China \\ ${ }^{2}$ State Key Laboratory of Disaster Reduction of Civil Engineering, Tongji University, 1239 \\ Siping Road, Shanghai, 200092, China \\ ${ }^{3}$ Corresponding author's e-mail: gilling_mao@163.com
}

\begin{abstract}
In recent years, building industry in China is experiencing upgrade and industrialization becomes popular. Container building has many advantages including low cost, high efficiency and clean construction. Therefore it is the most promising kind of industrialized building. The joint of boxes in container buildings is one of the main bottlenecks in restricting box-type architecture in multi-story and tall buildings. To solve this problem in box-type buildings, this paper present a new joint of boxes applied to a specific structural system named as column-bearing box-type modular system. The tensile capacity, shear capacity and corresponding failure modes of vertical two-box joint are obtained through experimental study. Meanwhile the flexural bending capacity and flexural stiffness of the vertical two-box joint are studied.
\end{abstract}

\section{KEYWORDS}

Prefabricated; container buildings; connection of boxes; frictional high-strength bolt; experimental study

\section{INTRODUCTION}

In recent years, building industry in China is experiencing upgrade and industrial architecture becomes popular. Container building has many advantages including low $\operatorname{cost}^{[1]}$, high efficiency ${ }^{[2,3,4]}$ and clean construction ${ }^{[5]}$. Therefore it is the most promising kind of industrial building ${ }^{[6]}$. Since China has high population density, in order to promote box-type buildings we need to expend its application range from low-story to multi-story or even high buildings. The joint of boxes in container buildings is one of the main bottlenecks in restricting box-type architecture in multi-story and tall buildings. Current joints of boxes in container buildings mainly have four kinds: welded joint ${ }^{[7]}$, corner fitting connection, block connection ${ }^{[8]}$ and column connection $^{[9]}$. These connections cannot take into account both capacity requirement of tall buildings and convenience of site construction.

To solve this problem in box-type buildings, this paper present a new joint of boxes applied to a specific structural system named as column-bearing box-type modular system.

\section{COLUMN-BEARING BOX-TYPE MODULAR SYSTEM}


The main load bearing elements in column-bearing modular box-type system include modular columns and beams. The vertical loads are transferred from slab to modular beams, and then to modular columns. Eventually modular columns pass the load to the foundation. The typical modular of column-bearing box-type system is shown in Figure 1. The size of a

modular is $6000 \mathrm{~mm}^{*} 2400 \mathrm{~mm} * 3100 \mathrm{~mm}\left(\mathrm{~L}^{*} \mathrm{~B} * \mathrm{H}\right)$. The section of modular columns is rectangular steel tube while the modular beams use cold-formed equilateral channel section, as shown in Figure 1 and Figure 2.

\section{JOINT SHAPE DESIGN}

According to the features of components in column-bearing modular structural system, the basic shape and force-transferring mechanism of the joint are designed.

The adjacent modular boxes are connected through modular side beams as shown in Figure 1 . The bottom side beams of upper modular box and the top side beams of lower modular box are connected to rectangular connection panels by high-strength bolts. The shear force in the joint can be transferred through the bolts in beam flanges directly, while it can also be transferred by the bolts in beam webs through the rectangular connection panels indirectly.

As shown in Figure 2, the adjacent boxes in same story are connected by the bolts in side beam webs, which take the shear force generated by the trend of horizontal displacement directly.

When experiencing earthquake or wind load, there may be tensile force in joints located in the peripheral boxes of the structure. The tensile force between vertical boxes is mainly transferred by the bolts in modular side beam webs and the rectangular connection panels. The bolts in side beam flanges can also provide partial tensile capacity.
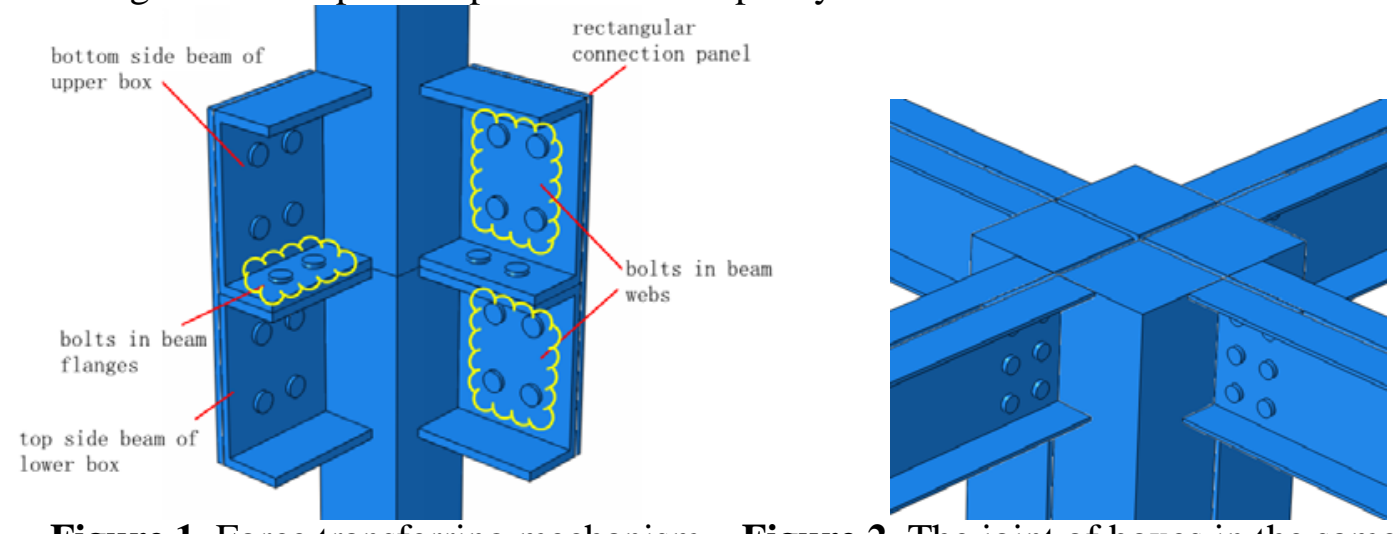

Figure 1. Force transferring mechanism Figure 2. The joint of boxes in the same story

To ensure that the joints can endure dynamic loads such as seismic load, the bolts used in the joints are all frictional type high-strength bolts.Inner diaphragms are placed inside the rectangular steel tube columns correspond to the locations of side beam flanges to avoid column wall damage.

Since the horizontal four-box joint and two-box joint are located in the roof of the whole structure, the loads in these two joints are small. Besides the force-transferring mechanism of these joints are quite simple. Therefore this paper doesn't conduct thorough research to these two 
kinds of joints. Because of the similarity in force-transferring mechanism, the capacity and performance of vertical four-box joint and eight-box joint can be deduced according to vertical two-box joint. Therefore this paper focuses on the mechanical performance of vertical two-boxes' joint.

\section{EXPERIMENTAL RESEARCH ON MECHANICAL BEHAVIOR OF VERTICAL TWO- BOX JOINT}

\section{Test purpose}

Through static tensile test, obtain the tensile, shear and two directions' flexural bending bearing performance of vertical two-box joint and the corresponding failure mode and ultimate bearing capacity.

\section{Specimens design}

The specimens for vertical two-box joint static tensile, shear and flexural bending tests are prototype. The specimens only keep the connection zone of the boxes. The bolts used in these joints are 10.9 M16 high-strength bolts. The modular columns and side beams are welded. The upper and lower modular boxes are connected through side beams by using high-strength-bolt frictional connection. Specimens use Q345B steel, the mechanical property parameters of which are obtained through material experiments.

\section{Test loading scheme}

The loading device for tensile test is an actuator which can provide 200-ton force at most. The loading device for shear test is a jack which can provide 50 -ton force at most. The loading device for both M1 and M2 directions are the same: a jack which can provide 20-ton force at most.

Test loading has two stages : preloading and formal loading. The purpose of preloading is to check the reliability of the test devices and ensure all the measuring equipments work well. Formal loading uses multi-stage loading. The loading ends until the specimen is damaged. When one of the following occurs, the specimen is considered damaged :

(1) The modular column damaged ;

(2) The modular side beam damaged ;

(3) The rectangular connection panel damaged ;

(4) The bolts damaged ;

(5) The joint occurs large local deformation ;

(6) The specimen cannot maintain the current load and the load-displacement curve starts to decline.

\section{Test process and phenomenon}

During the process of tensile loading, when the load is less than $300 \mathrm{kN}$, there is no obvious deformation in the modular columns, side beams and rectangular connection panels. The distance between the upper and lower columns is less than $1 \mathrm{~mm}$. After the load reached $300 \mathrm{kN}$, with the increase of the load, the distance between upper and lower modular columns begins to increase obviously while visible local deformation occurs on the flanges of the modular side beams. When the load reaches $700 \mathrm{kN}$, one of the lower modular side beams is cut, which lead to the damage of the joint, as shown in Figure 6. Meanwhile the distance between the upper and lower modular columns increases to about $35 \mathrm{~mm}$ and the flanges of the modular side beams occur 
large local deformations. The failure mode of the vertical two-box joint bearing tensile force is modular side beam damage, as shown in Figure 7.

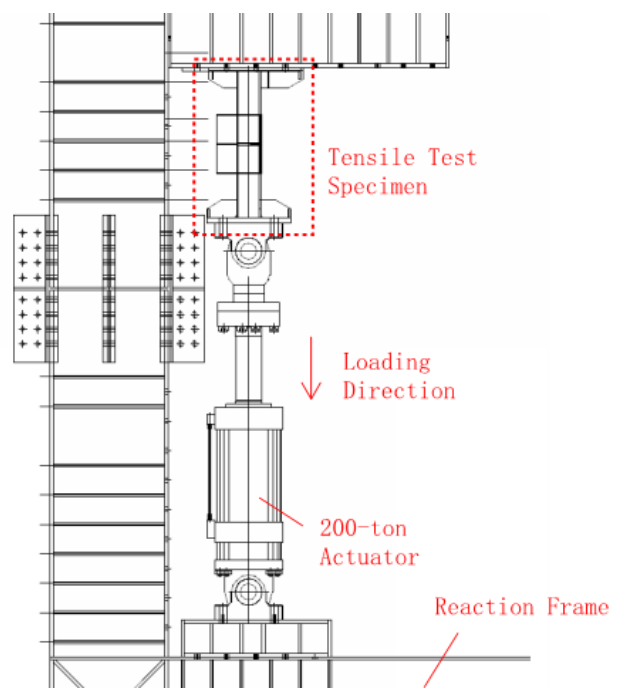

Figure 3. Tensile loading scheme diagram

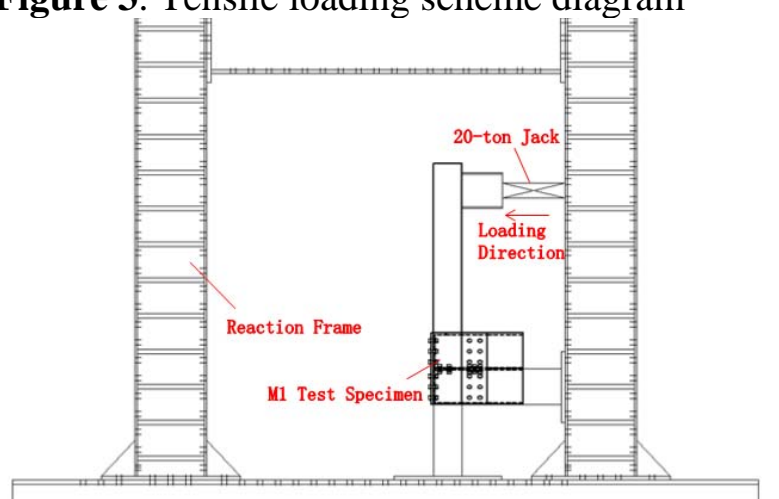

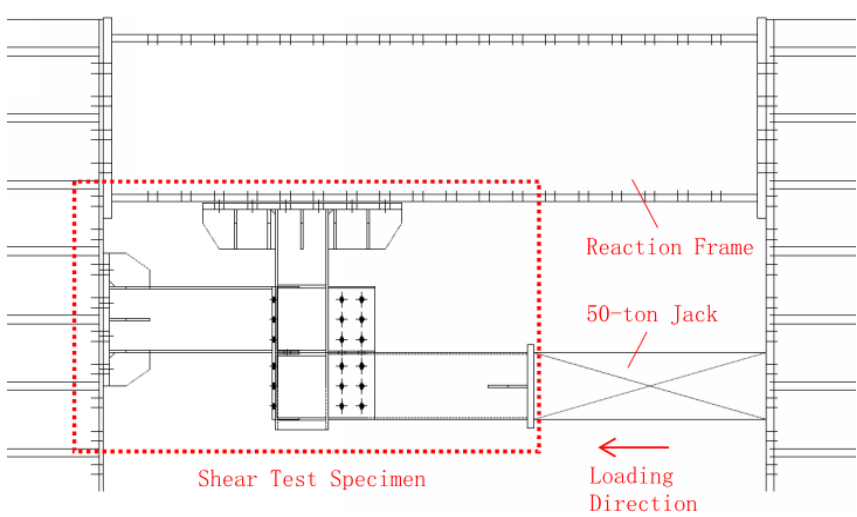

Figure 4. Shear loading scheme diagram

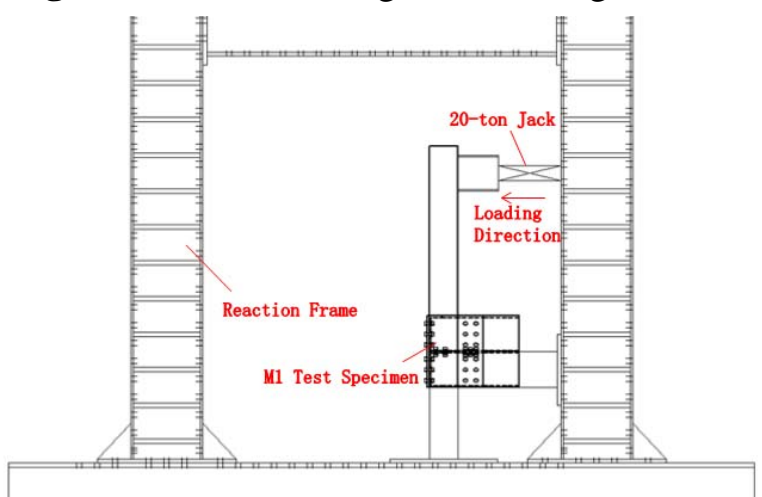

Figure 5. Flexural bending loading scheme diagram

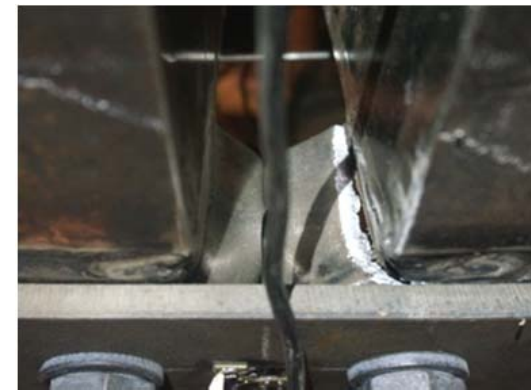

Figure 6. Deformation when loaded to $700 \mathrm{kN}$

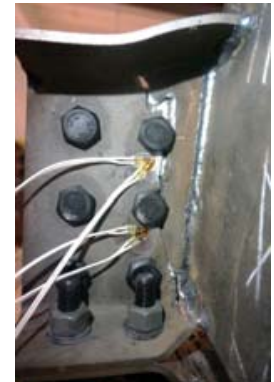

Figure 7. Tensile failure mode

During the process of shear loading, when the load is less than $250 \mathrm{kN}$, there is no obvious deformation in the modular columns, side beams and rectangular connection panels. The relative displacement between the upper and lower columns increases slowly to $2 \mathrm{~mm}$. After the load reached $250 \mathrm{kN}$, with the increase of the load, the relative displacement between upper and lower modular columns begins to increase obviously while the flanges of the modular side beams appears visible local deformation. When the load reaches about $440 \mathrm{kN}$, the flange of loading 
beam in upper modular occurs local buckling and the relative displacement between the upper and lower modular columns increases to about $10 \mathrm{~mm}$ as shown in Figure 8 . The failure mode of the vertical two-box joint bearing shear force is loading beam local buckling, as shown in figure 9 .
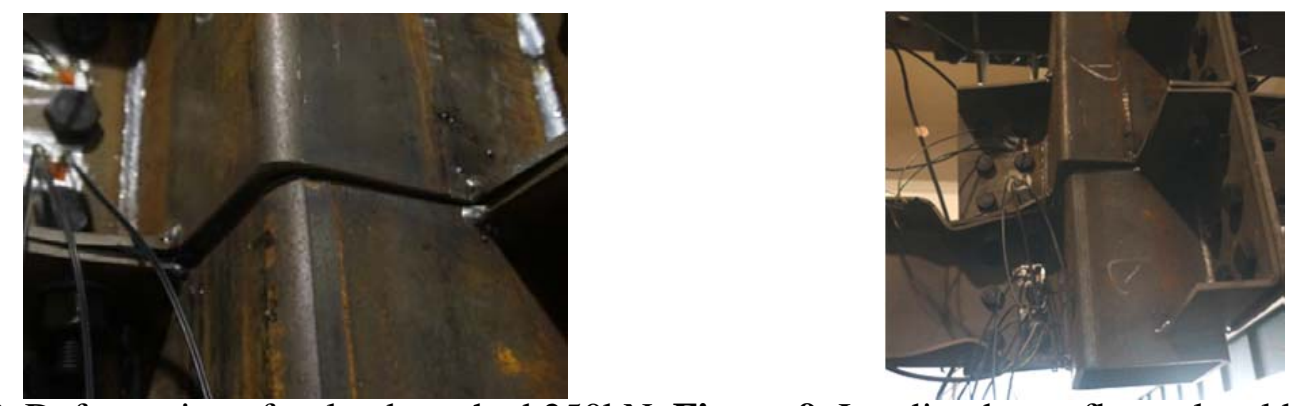

Figure 8. Deformation after load reached $250 \mathrm{kN}$ Figure 9. Loading beam flange local buckling

During the process of M1-direction loading, when the load is less than $60 \mathrm{kN}$, there is no obvious deformation in the modular columns, side beams and rectangular connection panels. The relative displacement between the upper and lower columns increases slowly to $3 \mathrm{~mm}$ and visible local deformation occurs on the tensile side beams' flanges. After the load reaches $60 \mathrm{kN}$, with the increase of the load, the relative displacement between upper and lower modular columns begins to increase rapidly, while the flanges of the modular side beams appears large local deformation and the rectangular connection penals show visible bending. When the load reaches about $82 \mathrm{kN}$, the angle of rotation is 0.05 , which is equivlant with a story drift of $1 / 20$ in the whole structure. At this moment the local deformations of the modular side beams are large and the rectangular connection panels bend obviously. The joint can be considered as damaged, as shown in Figure 10.
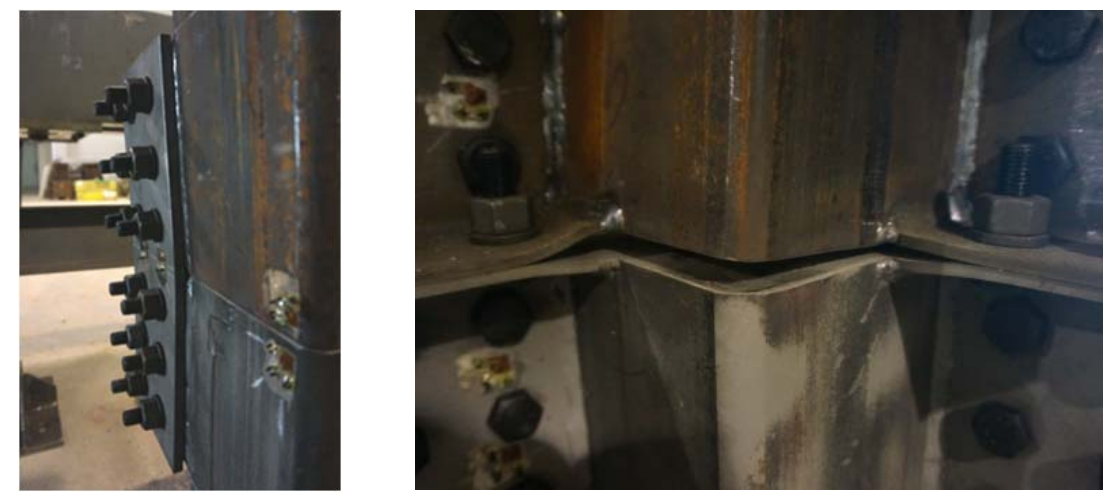

Figure 10. The joint's M1-direction flexural bending damage

During the process of M2-direction loading, when the load is less than $45 \mathrm{kN}$, there is no obvious deformation in the modular columns, side beams and rectangular connection panels. The relative displacement between the upper and lower columns increases slowly to $5 \mathrm{~mm}$ and visible local deformation occurs on the tensile side beams' flanges. After the load reaches $45 \mathrm{kN}$, with the increase of the load, the relative displacement between upper and lower modular columns begins to increase rapidly, while the flanges of the modular side beams' local deformations also enlarge and the rectangular connection penals show visible bending. When the load reaches about $58 \mathrm{kN}$, the angle of rotation is 0.04 , which is equivlant with a story drift of $1 / 25$ in the whole structure. At this moment the local deformations of the modular side beams are large and the rectangular 
connection panels bend obviously. The joint can be considered as damaged, as shown in Figure 11.
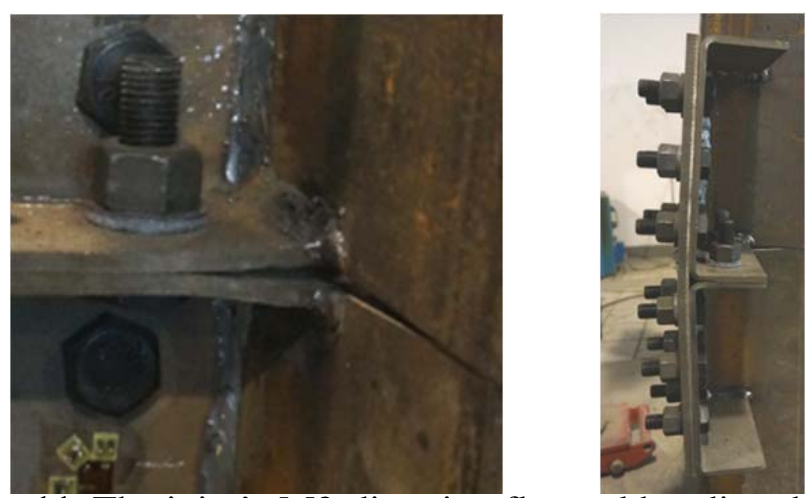

Figure 11. The joint's M2-direction flexural bending damage

\section{Test results analysis}

According to the measured data during the tensile test, the load-displacement curve of vertical two-box joint bearing tensile force is obtained, as shown in Figure 12. According to Figure 12, when the load reaches about $300 \mathrm{kN}$, the relative displacement of the upper and lower modular column is $0.7 \mathrm{~mm}$ and the curvature changes slightly, which indicates that the joint's tensile stiffness starts to decrease and the bolts in the connection zone may have slipped already. When the specimen is loaded to $400 \mathrm{kN}$, the relative displacement of the upper and lower modular column is $1.5 \mathrm{~mm}$ and the curvature declines obviously, which indicates that the joint's tensile stiffness decrease significantly and the components in the connection zone begin to yield. Combined with the test phenomenon can be concluded that the yielded components are modular side beams. The strain data extracted from the modular side beams shows that the beams start to yield in succession when the load reach from $380 \mathrm{kN}$ to $450 \mathrm{kN}$, which proves that the conclusion is correct. When the specimen is continuing loaded to the ultimate load $702 \mathrm{kN}$, the curve goes flat and smooth and the curvature changes slightly. During this process the relative displacement of the upper and lower modular column increases from $1.5 \mathrm{~mm}$ to $30 \mathrm{~mm}$ and the joint's tensile stiffness keep decreasing, which indicates that with the load increasing, the modular side beams gradually yield completely. After the load passes the ultimate value, the curve begins to decline. Then one of the modular side beams reaches to its ultimate capacity and ruptures, which leads to the damage of the joint. At this very moment the largest relative displacement of the upper and lower modular column is $38 \mathrm{~mm}$.
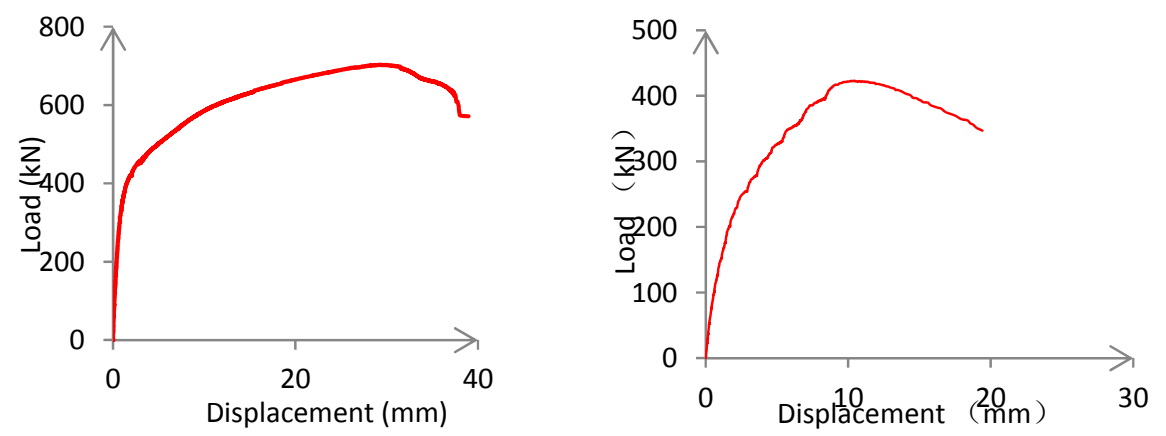

Figure 12. Tensile test load-displacement curve

Figure 13. Shear test load-displacement curve 
According to the measured data during the shear test, the load-displacement curve of vertical two-box joint bearing shear force is obtained, as shown in Figure 13. According to Figure 13, when the load reaches $220 \mathrm{kN}$, the relative displacement of the upper and lower modular column is near $2 \mathrm{~mm}$ and the curvature begins to change slightly. The data obtained by the strain gauges shows that at this moment both the modular side beams and the rectangular connection panels are still in elastic stress stage. Therefore the only reason that can lead to the change of the curve is that the bolts in connection zone begin to slip. When the specimen is loaded to $250 \mathrm{kN}$, the curvature declines obviously and the joint's shear stiffness decreases significantly. The strain gauges' data shows that the modular side beams and the rectangular connection panels are still in elastic stress stage, which indicates that multiple bolts in connection zone has already slipped. With the load increasing, the curvature declines rapidly and the joint's shear stiffness keep decreasing. When loaded to $440 \mathrm{kN}$, the loading beam's flange suddenly occurs local buckling. The specimen cannot maintain the current load and the load-displacement curve starts to decline. This phenomenon happens because the inevitable eccentric load occurs when loading. In real structutures story shears are not passed by the beam. Therefore such phenomenon only appears in test and is not the joint's real failure mode when bearing shear force.

According to the measured data during the flextural bending tests, the moment-rotation curves of vertical two-box joint bearing M1 and M2 direction flexural bending force is obtained, as shown in Figure 14 and 15. According to Figure 14, when the joint is bearing M1-direction flexural bending, the relationship of bending moment and rotation is linear before the moment reaches to $55 \mathrm{kN} \cdot \mathrm{m}$. The bending stiffness in M1-direction at this stage is $4888.6 \mathrm{kN} \cdot \mathrm{m} / \mathrm{rad}$. The data obtained by the strain gauges shows that at this moment both the modular side beams and the rectangular connection panels are still in elastic stress stage. When the bending moment is over $55 \mathrm{kN} \cdot \mathrm{m}$, the joint's bending stiffness drops rapidly to $478 \mathrm{kN} \cdot \mathrm{m} / \mathrm{rad}$, which is less than $1 / 10$ of the original bending stiffness. The data obtained by the strain gauges shows that the modular side beams and the rectangular connection panels gradually begin to yield with the load increasing.

According to Figure 15, when the joint is bearing M2-direction flexural bending, the relationship of bending moment and rotation is linear before the moment reaches to $40 \mathrm{kN} \cdot \mathrm{m}$. The bending stiffness in M1-direction at this stage is $3036.9 \mathrm{kN} \cdot \mathrm{m} / \mathrm{rad}$. The data obtained by the strain gauges shows that at this moment both the modular side beams and the rectangular connection panels are still in elastic stress stage. When the bending moment is over $40 \mathrm{kN} \cdot \mathrm{m}$, the joint's bending stiffness drops rapidly to $333 \mathrm{kN} \cdot \mathrm{m} / \mathrm{rad}$, which is about $1 / 10$ of the original bending stiffness. The data obtained by the strain gauges shows that the modular side beams and the rectangular connection panels gradually begin to yield with the load increasing.

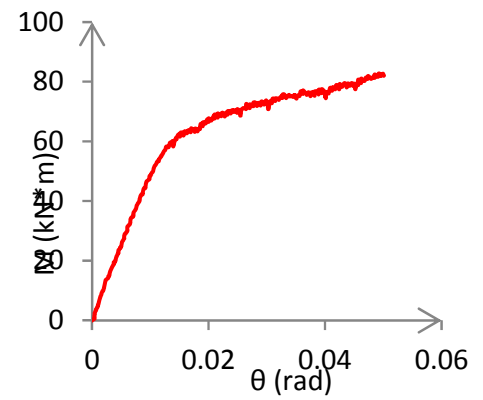

Figure 14. M1 moment-rotation curve

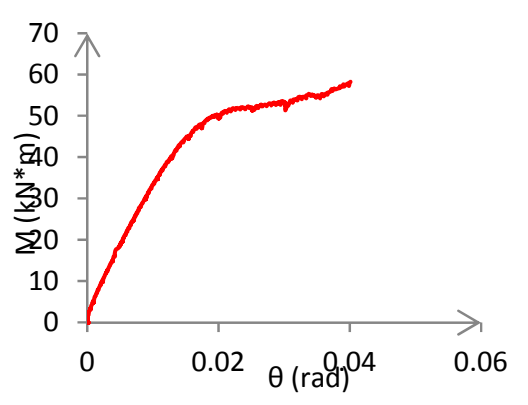

Figure 15. M2 moment-rotation curve 


\section{CONCLUSION}

From the experimental research on the vertical two-box joint, this paper mainly gets the following conclusions:

- The vertical two-box joint has good tensile capacity. The failure mode of the vertical two-box joint bearing tensile force is high-strength bolts slip. When the joint damages, its deformation is obvious and the relative displacement between upper and lower modular columns can reach over $30 \mathrm{~mm}$.

- The vertical two-box joint has good shear capacity. The failure mode of the vertical twobox joint bearing shear force is high-strength bolts slip. When the joint damages, its deformation is obvious and the relative displacement between upper and lower modular columns can reach to $10 \mathrm{~mm}$.

- The vertical two-box joint is semi-rigid and its flexural bending capacity is limited. The failure mode of the vertical two-box joint bearing flexural bending moment is highstrength bolts slip. Since the bending stiffness and capacity of this joint is so limited, it is suggested that this joint be considered as pinned connection in engineering designs.

\section{References}

[1] UITTENBROEK C, MACHT W. Sustainable containers cost-effective student housing[J]. Urban Development Journal, 2009(4): 53-60.

[2] HU Zhi Bin, WANG Yan Feng. Container Architecture's Design Feature and Maneuverability [J]. Knowledge Economy, 2010(16): 120

[3] YU Bao Da, YU Bao Ming. From Modular Modeling to Modular Construction [J]. Zhejiang Construction, 2013, 30(5): 56-59.

[4] ZHANG Jian, OU YANG Yu Chen, PU Qin, ETC. Simple Analysis of Container Buildings [J]. Charming China, 2010(1): 64.

[5] Anonymity. Container House from Alternative to Mainstream [J]. City and House, 2011(11): 80-81.

[6] GONG Xiao Lei, ZHANG Yu Kun. Transformation from Container to Building: An Attempt of the Sustainable Building Development [J]. World Architecture，2010(10): 124127.

[7] ZHA Xiao Xiong, ZHONG Jian Wei. Research on the Effects of Joint on the Container Building's Performance [C], Proceedings of the Steel Structure of Academic Convention, 2011: 46-47, 98.

[8] CECS_334-2013, Technical Specification for Modular Freight Container Building [S]. Beijing: China Planning Press, 2013.

[9] Anon. Yasutaka yoshimura architects: bayside marina hotel[EB/OL][2013-10-30]. http://www.designboom.com/architecture/yasutaka-yoshimura-architects-bayside-marina-hotel/. 